\title{
ANTROPOLOGÍA Y PALEOPATOLOGÍA DE LOS RESTOS ÓSEOS EXHUMADOS EN LA MAQBARA DEL TOSSAL DE MANISES (LA ALBUFERETA, ALICANTE)
}

\author{
ANTHROPOLOGY AND PALEOPATHOLOGY OF THE BONE REMAINS EXHUMED IN THE MAQBARA OF \\ THE TOSSAL DE MANISES (LA ALBUFERETA, ALICANTE)
}

\author{
CONSUELO ROCA DE TOGORES MUÑOZ \\ $M A R Q$, Alicante
}

Se estudian antropológicamente 68 esqueletos pertenecientes a los enterramientos hallados en la necrópolis islámica del Tossal de Manises (La Albufereta, Alicante) ${ }^{1}$.

La conservación de los huesos es muy deficiente, todos aparecen extremadamente fragmentados, con grandes pérdidas en las epífisis y con deterioros en el periostio, y muchos de los cráneos deformados por la presión de la tierra. Analíticas de la composición química del terreno confirmaron que el origen del deterioro óseo se debía a la alta concentración de sales que se observaba en el sedimento. Por ello fue necesaria una consolidación in situ antes de proceder a la exhumación de los restos, lo que ha provocado un costoso trabajo de eliminado de gasas con consolidante para proceder al estudio antropológico ${ }^{2}$.

Todo ello, a pesar de haber mermado los resultados del estudio antropológico y paleopatológico, ha permitido establecer las siguientes conclusiones:

Los restos óseos humanos estudiados, junto con los publicados por F. Rodes et alii (2000), corresponden a

1. El estudio completo está publicado en: Roca de Togores Muñoz, C., 2007: Estudio antropológico y paleopatológico, en A. Guilabert Mas et alii, La maqbara del Tossal de Manises (Alicante), tomo II: estudio antropológico, análisis sedimentológicos y óseos, resultados de las dataciones radiocarbónicas y musealización de la maqbara, M. Olcina Doménech et alii, La maqbara del Tossal de Manises (Alicante), Serie Excavaciones Arqueológicas, Memorias n ${ }^{\circ} 4,9-70$, Alicante.

2. La metodología empleada ha sido: métrica y morfología de R. Martin y K. Saller (1957). Edad en adultos: sinóstosis de las suturas craneales de F. Dérobert y G. Fully (1960), enfermedades degenerativas y desgaste dental de D. Brothwell (1987), edad en subadultos: fusión epífiso-diafisaria de los huesos largos de D. Brothwell (1987), desarrollo morfológico de los huesos de M. Stloukal y H. Hanakova (1978) y la formación dentaria de D.H. Ubelaker (1989) y G. Olivier (1960). Sexo características morfológicas sexuales de D. Ferembach et alii (1979) y G. Olivier y F. Demoulin (1976). Estatura tomada in situ y en laboratorio con fórmulas de M. Trotter y C.G. Glesser (en D. Campillo, 2001).
72 individuos, de los cuales 38 son adultos (entre 21 y 40 años), 4 son maduros (más de 40 años) y 7 son adultos indeterminados (entre 21 y 60 años). De entre los adultos, 18 son masculinos (cuatro probables) y 13 femeninos (tres probables), mientras que 18 no han podido ser determinados sexualmente. De la población subadulta 5 son adolescentes y 18 infantiles. La población infantil está representada casi totalmente por el segmento Infantil I (1-6 años), mientras que del segmento Infantil II (7-12 años) únicamente se ha encontrado un individuo de 10 años.

El análisis paleodemográfico (Fig. 1) muestra una población con un predominio de la mortalidad en la clase adulta (21-40 años) seguida por la de individuos infantiles I, entre el primer año de vida y los seis años, disminuyendo considerablemente durante los 7-12 años y manteniéndose durante el periodo juvenil. Existe un número importante de óbitos entre los tres-cuatro años de vida debido a que es una etapa crítica en la infancia, directamente relacionada con el periodo de destete. Pero la mortalidad se encuentra algo modificada en los individuos infantiles, pudiendo deberse, entre otros, a factores tafonómicos. La esperanza de vida al nacimiento de los individuos del Tossal de Manises no es muy elevada y se asemeja con la de otras sociedades medievales peninsulares y

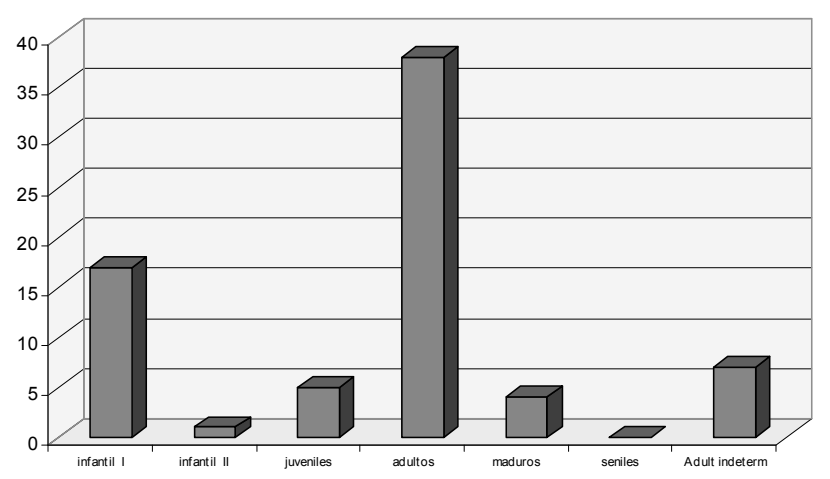

Figura 1: Distribución de la población por grupos de edad. 
europeas, todas ellas sometidas a unas condiciones de vida duras.

Se han comparando los resultados con dos series medievales estudiadas, el cementerio islámico de San Nicolás de Murcia (Bernis et alii, 1989) y el cementerio islámico de La Torrecilla en Granada (Souich, 1979) y se ha comprobado que demográficamente los grupos de edad infantil y juvenil se asemejan mucho con la de Tossal mientras que el grupo de los adultos, en esta última, sube en detrimento de los maduros, representado por poco más de un $5 \%$, que seguramente se deba a la dificultad en el estudio antropológico por la pésima conservación de los restos óseos.

Son mediterráneos gráciles, poseen un cráneo medianamente largo y de anchura media, una cara alta y estrecha, órbitas subcuadrangulares medianamente altas, una nariz alta y estrecha y una mandíbula de tamaño medio y poco robusta. Su estatura es mediabaja, $168 \mathrm{~cm}$ para los varones y $159 \mathrm{~cm}$ para las mujeres. Se puede decir que esta población es bastante homogénea y no presenta diferencias significativas morfométricas con respecto a otras poblaciones islámicas.

Se han podido documentar muy pocas patologías que dejaran impronta en el hueso, debido a la pésima conservación del mismo, aunque sí se han observado enfermedades orales que ponen de manifiesto la existencia de procesos cariosos, desgastes, sarro, hipoplasia dental, pérdidas ante mortem, periodontitis y agenesias dentarias.

Además se realizó un estudio del cráneo del enterramiento 42 (Fig. 2) a través de la tomografía computarizada (TAC), que sin eliminar el engasado con consolidante que lo envolvía permitía estudiar métrica y morfológicamente el cráneo observándolo mediante imágenes de cortes axiales y coronales así como tridimensionalmente.

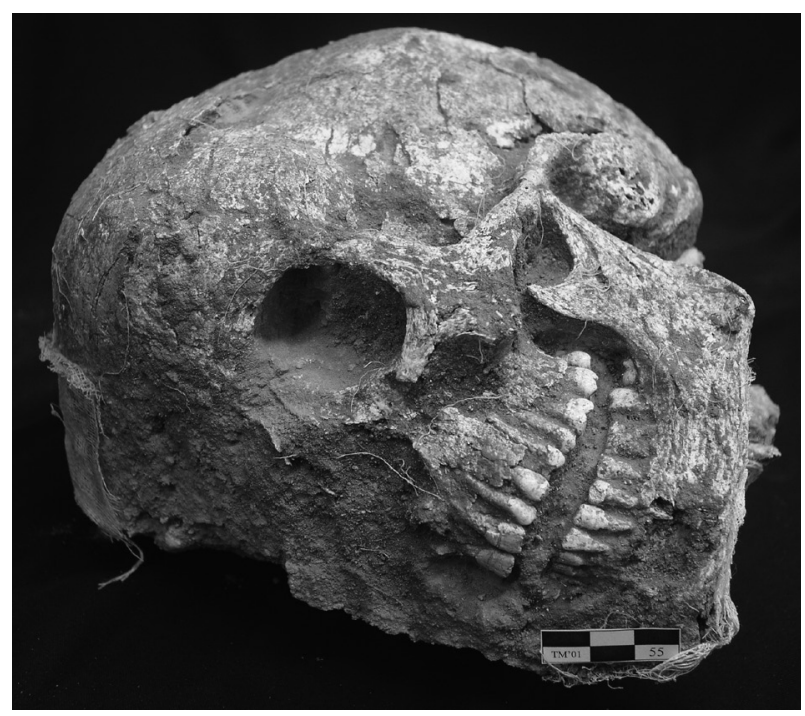

Figura 2: Cráneo del enterramiento $\mathrm{n}^{\mathrm{o}} 55$, una vez eliminadas las gasas con consolidante.
También se realizaron radiografías a piezas dentarias aisladas correspondientes a los individuos 38, 68 y 87 , que son de gran utilidad en el diagnóstico de la edad y patologías. Asimismo se realizaron análisis de microestriación en dientes mediante microscopía electrónica de barrido (SEM). La microestriación dentaria es uno de los indicadores paleonutricionales que sirve para acercarnos al estudio de la dieta y de los hábitos alimentarios y culturales, en definitiva, de la reconstrucción de los modos de vida de poblaciones antiguas. La técnica es analizar la longitud, orientación y forma de las estrías que aparecen en el esmalte del diente y que son producidas por el alimento durante el proceso masticatorio. Los resultados indican un mayor número de estrías verticales que orientan hacia una dieta más rica en el consumo de vegetales, cereales y leguminosas, utilizados principalmente para la elaboración del pan, gachas y tortas.

\author{
Consuelo Roca de Togores Muñoz \\ MARQ, Alicante \\ Plaza Doctor Gómez Ulla s/n \\ 03013 Alicante \\ crocat@dip-alicante.es
}

\section{BIBLIOGRAFÍA}

BERnis, C., GARCÍA, L. y RoBles, M., 1985: «El cementerio islámico de San Nicolás: Aspectos demográficos», I Congreso de Arqueología Medieval Española, vol. IV.

Brothwell, D.R., 1987: Desenterrando Huesos. La excavación, el tratamiento y estudio de los restos del esqueleto humano, México.

CAMPILlO, D., 2001: Introducción a la Paleopatología, Barcelona.

DÉrobert, F. y Fully, G., 1960: «Étude critique de la valeur du degré d'oblitération des sutures craniennes pour la détermination de l'âge, d'aprés l'examen de 480 crânes», Annales de Médicine Légale, T. 40, n 2, 154-165.

Du Souich, PH., 1979: «Estudio antropológico de la necrópolis medieval de La Torrecilla (Arenas del Rey, Granada)», Antropología y Paleoecología Humana, 1, 27-40.

Ferembach, D., Schwidetzky, I. y Stloukal, M., 1979: «Recommandations pour déterminer l'age et le sexe sur le squelette», Bulletin et Mémoire de la Societé d'Anthropologie de Paris, T 6, Série XIII, 7-45.

MARTIN, R. y SALleR, K., 1957: Lehrbuch der Anthropologie. I. Stuttgart.

Olivier, G., 1960: Pratique Anthropologique. Paris.

Olivier, G. y Demoulin, F., 1976: Pratique Anthropologique à l'usage des étudiants, Paris.

Roca De Togores Muñoz, C., 2007: Estudio antropológico y paleopatológico, en A. GUILABERT MAS ET ALII, La maqbara del Tossal de Manises (Alicante), tomo II: estudio antropológico, análisis sedimentológicos y óseos, resultados de las dataciones radiocarbónicas y musealización de la maqbara, M. OLCINA DOMÉNECH 
ET ALII, La maqbara del Tossal de Manises (Alicante), Serie Excavaciones Arqueológicas, Memorias $\mathrm{n}^{\mathrm{o}} 4$, 9-70, Alicante.

Rodes Lloret, F., Chiarri Rodrigo, J., Cloquell RoDRIGO, B., MARTÍ LLORET, J.B., 2000: Estudio de cuatro esqueletos humanos islámicos del Tossal de Manises (Alicante). Elche.

UBELAKER, D.H., 1994: Human skeletal remains. Excavation, analysis, interpretation, Manuals on Archeology, 2. Taxacorum. Washington. 